\title{
Effects of the Poloidal Variation of the Magnetic Field Ripple on Enhanced Heat Transport in Tokamaks
}

\author{
N. A. Uckan \\ K. T. Tsang \\ J. D. Callen
}




\section{DISCLAIMER}

This report was prepared as an account of work sponsored by an agency of the United States Government. Neither the United States Government nor any agency Thereof, nor any of their employees, makes any warranty, express or implied, or assumes any legal liability or responsibility for the accuracy, completeness, or usefulness of any information, apparatus, product, or process disclosed, or represents that its use would not infringe privately owned rights. Reference herein to any specific commercial product, process, or service by trade name, trademark, manufacturer, or otherwise does not necessarily constitute or imply its endorsement, recommendation, or favoring by the United States Government or any agency thereof. The views and opinions of authors expressed herein do not necessarily state or reflect those of the United States Government or any agency thereof. 


\section{DISCLAIMER}

Portions of this document may be illegible in electronic image products. Images are produced from the best available original document. 
Printed in the United States of America: Available from National Technical Information Service

U.S. Department of Commerce

5285 Port Royal Road, Springficld, Virginia 22161

Price: Printed Copy \$4.00; Microfiche \$2.25

This report was prepared as an account of work sponsored by the United States Government. Neither the United States nor the Energy Research and Development Administration/United States Nuclear Regulatory Commission, nor any of their employees, nor any of their contractors, subcontractors, or their employees, makes any warranty, express or implied, or assumes any legal liability or responsibility for the accuracy, completeness or usefulness of any information, apparatus, product or process disclosed, or represents that its use would not infringe privately owned rights. 
Thermonuclear Division

\section{EFFECTS OF THE POLOIDAL VARIATION OF THE MAGNETIC FIELD RIPPLE ON ENHANCED HEAT TRANSPORT IN TOKAMAKS}

N. A. Uckan, K. T. Tsang, and J. D. Callen

Oak Ridge National Laboratory, Oak Ridge, Tennessee 37830

JUNE 1976

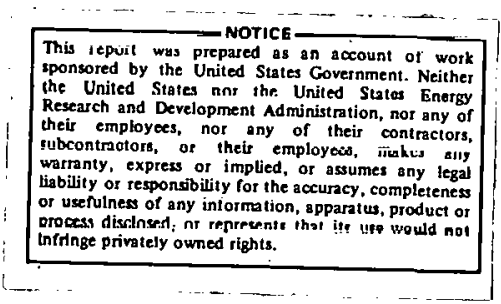

OAK RIDGE NATIONAL LABORATORY

Oak Ridge, Tennessee 37830 operated by

UNION CARBIDE CORPORATION

for the

ENERGY RESEARCH AND DEVELOPMENT ADMINISTRATION 
EFFECTS OF THE POLOIDAL VARIATION OF. THE MAGNETIC FIELD

RIPPLE ON ENHANCED HEAT TRANSPORT IN TOKAMAKS*

\author{
N. A. Uckan, K. T. Tsang, and J. D. Callen \\ Oak Ridge National Laboratory, Oak Ridge, Tennessee 37830
}

\title{
ABSTRACT
}

The use of a finite number of coils to generate the toroidal field of a tokamak introduces a magnetic field asymmetry and is responsible for an additional particle trapping that can affect the plasma confinement. The enhanced transport coefficients associated with the ripple-induced drifts have been calculated. The calculations include both the radial and poloidal variation in the magnitude of the field ripple. It is found that the consideration of poloidal variation significantly reduces the rippletrapped transport but does not affect the banana-drift diffusion. Results relevant to the ORNL Experimental Power Reactor (EPR) reference design are discussed.

\section{INTRODUCTION}

In the design of tokamak devices, the ripple produced by the finite number of toroidal field coils destroys the ideal axisymmetry of the configuration and is responsible for additional particle trapping. In the region of low collision frequencies, the magnetic field ripple might be the main factor determining the transport of particles and energy. ${ }^{1-3}$ The ripple can lead to plasma transport by two separate mechanisms. In the first, known as ripple trapping, the particles become trapped in a

\footnotetext{
*Research sponsored by the Energy Research and Development Administration under contract with Union Carbide Corporation.
} 
toroidal field minimum between coils that are localized in the toroidal direction, hence also in the poloidal direction, and experience a unidirectional toroidal drift which leads to the ripple diffusion. ${ }^{-3}$ The ripple trapping affects only a relatively small group of particles, namely those with $v_{\|}$(parallel velocity) so small that they can be trapped in the ripple. Those particles trapped in the toroidal field and executing banana orbits experience a new radial drift. of their banana guiding. center due to the presence of ripples, which leads to another kind of diffusion called the banana drift diffusion."

In the literature different authors ${ }^{2-4}$ have considered these two effects with a radial variation only. In practice, the ripple mndulation $\delta$ is also dependent on the poloidal variation. The poloidal variation has the effect of reducing or completely eliminating the ripple well depth on the inside of the torus, with the precise degree of reduction depending on the shape of the coil and the position of the plasma in the coil. In this regard, the previous calculations have overestimater the ripple effects through neglect of this poloidal variation.

The purpose of the present work is to calculate the enhanced transport losses due to field ripple, including both the radial and poloidal variation, as is appropriate for the design of future tokamaks.

In Section 2, the magnetic well depth for a rippled toroidal field is derived. Threshold and critical energies assuciated with the ripples are obtained in Section 3. This leads to a number of ripple collisionality regimes, each of which can be characterized by simple random walk argument for the illustration of ripple trapped diffusion ${ }^{2,3}$ and banana drift diffusion. ${ }^{4}$ In Section 4 , we derive the corresponding analytical 
expressions by solving the drift kinetic equation with the appropriate limit. In Section 5, we present the numerical results of the heat conduction losses in the design of ORNL EPR. ${ }^{5}$

\section{MAGNETIC WELL DEPTH}

For a simple model of tokamak confinement geometry, the resulting magnetic field can be written as ${ }^{1-3}$

$$
\underline{B}=\frac{B_{0}}{h}\left(\frac{B_{r}}{B_{\phi}}, \theta, 1-\delta(r, \theta) \cos N \phi\right)
$$

where $r$ and $\theta$ are polar co-ordinates in the minor cross section of the torus, and $\phi$ is the angular co-ordinate along the magnetic axis;

$h=1+\left(r / R_{0}\right) \cos \theta=1+\varepsilon \cdot \cos \theta ; \delta(r, \theta)=\left(B_{\max }-B_{\min }\right) /\left(B_{\max }+B_{\min }\right)$ $<r / R_{0}$ is the depth of the ripples; $N$ is the number of toroidal field coils; and $\theta=\varepsilon / q$ with $q$ being the safety factor. The radial component of $\underline{B}$ necessary to satisfy $\nabla \cdot \underline{B}=0$ can be found from

$$
\frac{\partial}{\partial \cdot r}\left(r h B_{r}\right)+\frac{r}{R_{0}} \frac{\partial}{\partial \phi}\left(B_{\phi}\right)=0,
$$

which is on the order of $B_{r} \sim \delta B_{0} \sin N \phi$. Hence the field strength is approximately

$$
B \simeq B_{\phi}=B_{0}[1-\varepsilon \cos \theta-\delta(r, \theta) \cos N \phi] .
$$

It is clear from Eq. (3) that the magnetic well depth on a fixed magnetic surface $(r=$ const) depends on: 1) the decrease of the toroidal magnetic field with increasing distance from the major axis of the system; and 2) the dependence of the $\delta(r, \theta)$ on poloidal variation $\theta$. 
The actual relationship of $\delta$ to $r$ and $\theta$ depends substantially on the coil design and on the size and shape of the gap between the coils. In a typical case, to find the function $\delta(r, \theta)$, we must carry out computer calculations for the particular magnet design. However, a great number of calculations have shown that it is possible to write an approximate expression for the ripple $\delta(r, \theta)$, which is suitable for the purpose of our calculations, as

$$
\begin{aligned}
\delta(r, \theta) & =\delta(r) g(\theta) \\
& =\delta_{a}\left[\frac{\delta_{0}}{\delta_{a}}+(r / a)^{n}\right] \exp \left(-B \theta^{2}\right)
\end{aligned}
$$

where $a$ is the $n$ lasma radius; $\delta_{0}$ and $\delta_{a}$ are the values ur $\delta$ at $r=0$ and $r=a$, respectively, with $\delta_{0} / \delta_{a} \sim 10^{-3}-10^{-4}$; and $\beta$ is a parameter which can be determined from the calculations and closely depends on the shape of the coils and plasma locations - usually, $0.5 \leqslant \beta \leqslant 1$.

Along the field line $\phi \simeq q \theta$, the variation in the field strength, for the $\underline{B}$ field given in Eq. (3); is

$$
\begin{aligned}
\frac{1}{B_{0}} \frac{\partial B}{\partial S} & =\frac{1}{R_{0}}\left[\frac{\varepsilon}{q} \sin \theta+N \delta(r, \theta) \sin N \phi+\frac{1}{q} \frac{\partial \delta(r, \theta)}{\partial \theta} \cos N \phi\right] \\
& \simeq \frac{N \delta(r, \theta)}{R_{0}}[\alpha(r, \theta) \sin \theta+\sin N \phi],
\end{aligned}
$$

where $a(r, \theta)=\varepsilon / N q \delta(r, \theta)$. In Eq. (5) the term $\frac{1}{q} \frac{\partial \delta(r, \theta)}{\partial \theta}$ has been neglected in comparison with the term $N \delta(r, \theta)$. Since the variation in $\theta$ over one ripple period, $2 \pi / \mathrm{Nq}$, is small, the condition for a ripple well to occur, given by $\partial B / \partial S=0$, is

$$
\alpha(r, \theta)|\sin \theta|<1
$$


When the condition expressed in Eq. (6) is satisfied, the positions of the maxima and minima of the field along the field line are determined by the equation

$$
\alpha(r, \theta) \sin \theta+\sin N \phi=0
$$

The magnetic well depth $\Delta(r, \theta)$ is expressed as the difference between the values of the neighboring maxima and minima and is given by

$$
\begin{aligned}
\Delta(r, \theta) & =\frac{B_{\text {max }}-B_{\text {min }}}{B_{0}} \\
& =2 \delta(r, \theta)\left\{\sqrt{1-\alpha^{2}(r, \theta) \sin ^{2} \theta}\right. \\
& \left.-\alpha(r, \theta)\left[\pi / 2-\sin ^{-1} \cdot(\alpha(r, \theta) \cdot|\sin \theta|)\right]|\sin \theta|\right\}
\end{aligned}
$$

We should note that Égs. (5) through (8) are the same set of relations obtained in Refs. 2 and 3 except for the explicit dependence of ripple $\delta(r, \theta)$ on poloidal angle $\theta$, given by Eq. (4), which in fact gives an explicit dependence of $\theta$ on $\alpha(r, \theta)$. We can define $\alpha(r, \theta)$ as

$$
\alpha(r, \theta)=\frac{\alpha(r)}{g(\theta)}=\alpha(r) e^{\beta \theta^{2}}
$$

with $\alpha(r)=\varepsilon / \mathrm{Nq} \delta(r)$. Estimates by Stringer ${ }^{2}$ and by Connor and Hastie ${ }^{3}$ of the reduction in diffusion and ion heat conductivity are obtained by taking account of this reduction in well depth from $2 \delta(r)$ to $\Delta(r, \theta)$. Although this effect is of great importance it neglects the distortion of the ripple wells due to the additional influence of the poloidal angle variation in the field ripple strength. It is obvious that the factor $\delta(r, \theta)$ in front of the expression. $\Delta(r, \theta)$ helps to decrease the well depth for a $\theta$ close to $\pm \pi$ (inner edge of the torus). The $\theta$ 
dependence of $\alpha$ helps to el iminate the well completely for $\theta$ near $+\Pi$. It will be shown that the consideration of the poloidal variation in the case of actual magnetic fields significantly reduces the transport losses (by about a factor of about 10 in comparison with the results of Refs. 2 and 3 ) for $\alpha(r)$ between 0 and 1.5, which is the most important range of $a(r)$ for practical purposes.

\section{CRITICAL ENFRGIFS}

The first point to consider is the threshold energy above which particles execute more than one bounce motion in a ripple before being scattered out of the loss region $\left(v_{11}<\delta^{1 / 2} v_{\perp}\right)$ associated with the ripples. This energy is defined by setting ${ }^{1}$

$$
\begin{array}{r}
\tau_{\text {scattering }}=\tau_{\text {bounce }} \\
\text { or } \quad \delta / v=R_{0} / \delta^{1 / 2} \vee N,
\end{array}
$$

with $v$ being the collision frequency and $v$ the particle speed. Taking account of the fact that the collision frequency varies as $v^{-3}$, this relation, for ions, can be reduced to:

$$
E_{t h} \simeq \delta^{-3 / 4}\left(R_{0} / N\right)^{1 / 2}\left[8 \times 10^{-13} n_{e} Z_{e f f}\right]^{1 / 2}(e V)
$$

The threshold energy is a factor of $\left(m_{1} / m_{e}\right)^{1 / 4}$ larger for clcctrons. For the present (future) tokamaks, the ion threshold energy is typically on the order of $.3 \mathrm{keV}(3 \mathrm{keV})$ at the plasma edge and a factor of about $10^{2}$ (50) larger at the plasma center (see Table 1).

The second point to consider is that when a particle has been trapped in a ripple, its guiding center drifts more or less along a contour of 
constant B. Since such contours are not closed within the torus for weak ripples, the particles are not confined unless they are scattered out of the ripple loss region before they can reach the wall. This consideration defines a critical energy, above which a particle will reach the wall if it is trapped in the ripple, determined by ${ }^{1}$

$$
\tau_{\text {scattering }}=\tau_{\text {drift }}=a / v_{\text {drift }} \text {, }
$$

where

$$
v_{\text {drift }} \cong \frac{\mathrm{CE}}{\mathrm{eBR_{0 }}}=10^{8} \frac{\mathrm{E}(\mathrm{eV})}{\mathrm{B}(\text { gauss }) \mathrm{R}(\mathrm{cm})}(\mathrm{cm} / \mathrm{sec}) \text {. }
$$

For ions this gives a critical energy (in eV) of

$$
E_{\star} \simeq\left[10^{-14} \frac{B R_{o} a}{\delta} n_{e} z_{e f f}\right]^{2 / 5}
$$

The critical energy is a factor of $\left(m_{j} / m_{e}\right)^{1 / 5}$ larger for electrons. Again considering a typical present (future) tokamak base case, we can find the critical ion energy to be on the order of $10 \mathrm{keV}(50 \mathrm{keV})$ at the plasma edge and a factor of about 10 (10) greater near the plasma center (see Table 1). We show illustrative values of these two "critical" ion energies for various values of $\delta$ in Fig. 1 .

With these critical energies we can see that the ripple collisionality regime can be divided into three regions as shown in Fig. 2 . The upper collision frequency point $\left(\nu>v N \delta^{3 / 2} / R\right)$, above which transport losses rapidly diminish to zero, is the point at which the plasma particle temperature decreases below the threshold energy. In the middle range of the collisionality regime $\left(\rho v \delta / R a<\nu<v N \delta \delta^{3 / 2} / R\right.$ where $\rho=v / \Omega$ is the Larmor radius), transport coefficients scale as $\nu^{-1}$ because the 
particles are scattered out of the loss region before they can drift completely out of the device. To convey the spirit of simple diffusion estimates, we include in this section only a rough picture of random walk losses. The average step taken by a ripple-trapped particle is

$$
(\Delta r)^{\delta} \sim v_{\text {drift }} \cdot{ }^{\delta}{ }_{\text {eff }}^{\delta}=v_{\text {drift }} \cdot \frac{\delta}{v}
$$

and that taken by a banana-drift particle is

$$
(\Delta r)^{B D} \sim v_{B D} \cdot \tau_{e f f}^{\varepsilon}=\left(v_{\text {drift }} N \delta\right) \cdot \frac{\varepsilon}{\nu} .
$$

The frequency with which such steps can be taken is $\nu / \delta$ and $\nu / \varepsilon$ respectively. The fraction of particles for these processes is $\sqrt{\delta}$ and $\sqrt{\varepsilon}$; so that

$$
D^{\delta} \sim\left[(\Delta r)^{\delta}\right]^{2}(\nu / \delta) \delta^{1 / 2} \sim \frac{\delta^{3 / 2} v_{\mathrm{drift}}^{2}}{\nu}
$$

and

$$
D^{B D} \sim\left[(\Delta r)^{B D}\right]^{2} \cdot(\nu / \varepsilon) \varepsilon^{1 / 2} \sim \varepsilon^{3 / 2} \cdot s^{2} N^{2} \cdot \frac{v_{d r i f t}^{2}}{v} .
$$

Finally, at very low collision frequencies ( $v<0 v \delta / R a)$, the particle temperature has increased above the critical energy, and all particles trapped in the ripples immediately drift to the wall without being scattered out of the loss region. The corresponding diffusion coefficient is

$$
D \sim v \mathrm{a}^{2}
$$

The variation of diffusion and heat conductivity with collision frequency is illustrated schematically in Fig. 2. 


\section{CALCULATION OF TRANSPORT MODIFICATIONS}

The dominant transport modifications come from the enhanced ion heat conduction of the background plasma resulting from the ripple trapping of ions with energies exceeding the threshold energy and from rippleinduced banana-drift. (The effect on electron heat conduction is much smaller because the threshold energy is much higher.) From the estimates of $E_{t h}$ and $E_{\star}$ given in the previous section, we can see that for plasma ion temperatures anticipated in present and future tokamaks to be in the range of $E_{t h}<T_{i}<E_{\star}$, the relevant ion thermal conductivity coefficient $x_{j}$. is in the middle range of collisionality.

\subsection{Ripple-Trapped Diffusion}

The expression for the ion heat conductivity coefficient in the above-mentioned regime has been derived by Stringer ${ }^{2}$ and by Connor and Hastie $^{3}$ :

$$
x_{i}^{\delta}=46.5 \frac{\delta^{3 / 2} G(\alpha, \beta)}{v_{i i}} v_{d r i f t}^{2}
$$

where

$$
G(\alpha ; \beta)=\frac{1}{\pi} \int\left[\frac{\Delta(r, \theta)}{2 \delta(r)}\right]^{3 / 2} \sin ^{2} \theta d \theta
$$

Using Eq. (8) in Eq. (20),

$$
\begin{aligned}
G(\alpha, \beta) & =\frac{2}{\pi} \int_{C} d \theta \sin ^{2} \theta[g(\theta)]^{3 / 2}\left[\sqrt{1-\alpha^{2}(r) \sin ^{2} \theta / g^{2}(\theta)}\right. \\
& -\frac{\alpha(r)}{g(\theta)}|\sin \theta|\left\{\frac{\pi}{2}-\sin ^{-1}\left[\frac{\alpha(r)}{g(\theta)}|\sin \theta| \mid\right\}\right]^{3 / 2}
\end{aligned}
$$

with

$$
\int_{c}=\int_{0}^{\theta_{i}}+\int_{\theta_{2}}^{\pi}
$$


where $\theta_{1}$ and $\theta_{2}$ are the zeros of the term under the square root in square brackets. The computed value of $G(\alpha, \beta)$ for different $\beta$ values is plotted against $\alpha(r)$ in Fig. 3. Comparison with the correction factors $I(\alpha)$ obtained by Stringer ${ }^{2}$ and $G(\alpha)$ obtained by Connor and Hastie, ${ }^{3}$ shows that where $\beta=0, G(\alpha, \beta) \ll I(\alpha)$ or $G(\alpha)$ for all $\alpha(r)$, and that $G(\alpha, \beta)$ $I(\alpha) / 10$ for most of the range of interest of $\alpha(r)$. Thus the diffusion estimates of Refs. 2 and 3 are significant overestimates.

\subsection{Banana-Drift Diffusion}

To compute the banana guiding center motion, we use the conservation of $\mathrm{J}$ :

$$
J=\oint v_{\|} d l=\int d l[2(E-\mu B)]^{l / 2}
$$

Using Eq. (4) in Eq. (2), we have

$$
B_{r} \cong-\frac{\delta}{h^{2}} \frac{B_{0} N}{n+2} \frac{r}{R_{0}} \sin N \phi \text {. }
$$

The line of force is then defined by

$$
\begin{gathered}
\frac{d r}{d \theta}=r \frac{B_{r}}{B_{\theta}} \simeq-\frac{r q}{h} \delta(r, \theta) \frac{N}{n+?} \sin N \phi ; \\
\frac{d \phi}{d \theta} \equiv \frac{r}{R} \frac{B_{\phi}}{B_{\theta}}=\frac{q}{h}(1-v(r, \theta) \cos N \psi)
\end{gathered}
$$

To the lowest order, $\phi=q^{\theta}+\tau$, where $\tau$ is the initial position in $\phi$, and

$$
r=r_{0}\left[1-q \delta(r) \frac{N}{n+2} \int_{0}^{\theta} g(\theta) \sin (N q \theta+N \tau) d \theta\right]
$$


Thus we have

$$
J=J_{0}+J_{1}\left[\frac{\delta(r, \theta)}{g(\theta)}\right]=J_{0}+J_{1} \delta(r)
$$

where

$$
\begin{aligned}
& J_{0}=4\left(\mu B_{0} \varepsilon\right)^{1 / 2} R_{0} q \int_{0}^{\theta} d \theta\left(M-\sin ^{2} \frac{\theta}{2}\right)^{1 / 2} \\
& J_{1}=4 R_{0} q\left(\mu B_{0} \varepsilon\right)^{1 / 2} \cos N \tau I \\
& I=\int_{0}^{\theta_{0}} d \theta\left\{-\left[h g(\theta) \cos N q \theta+\frac{Q N q}{n+2} \int_{0}^{\theta} g(\theta) \sin N q \theta d \theta\right]\right. \\
& \left.\cdot\left(M-\sin ^{2} \frac{\theta}{2}\right)^{1 / 2}+\frac{h g(\theta) \cos N q}{4 \varepsilon\left(M-\sin ^{2} \frac{\theta}{2}\right)^{1 / 2}}\right\} \\
& M=\left[E-\mu B_{0}(1-\varepsilon)\right] / 2 \mu B_{0} \varepsilon \\
& \theta_{0}=2 \sin -1 \cdot \sqrt{M} \\
& Q=d \ln q / d \text { en } r
\end{aligned}
$$

To evaluate I, we first look at the term with $Q$ in I:

$$
\begin{aligned}
& \int_{0}^{\theta} g(\theta) \sin N q \theta d \theta=\operatorname{Im} \int_{0}^{\theta} \exp \left(-\beta \theta^{2}+I N q \theta\right) d \theta \\
& =\operatorname{Im}\left[1 / 2(\pi / \beta)^{1 / 2} \exp \left[-\frac{(N q)^{2}}{4 \beta}\right] \quad \cdots\right. \\
& \quad \times\left[\operatorname{erf}\left(\beta^{1 / 2} \theta-\frac{i N q}{2 \beta}\right)-\operatorname{erf}\left(-\frac{i N q}{2 \beta}\right)\right]
\end{aligned}
$$

Since $\left|\beta^{1 / 2} \theta-\frac{i N q}{2 \beta T / 2}\right| \gg 1$, we can use the asymptotic form for $\operatorname{erf}(z)$ to obtain 


$$
\begin{aligned}
\int_{0}^{\theta} g(\theta) \sin N q & \simeq \frac{1}{N q}-\frac{e^{-\beta \theta^{2}}}{4 \beta^{2} \theta^{2}+(N q)^{2}}[\beta \theta \sin N q \theta \\
& +N q \cos N q \theta]
\end{aligned}
$$

Since $\mathrm{Nq} \gg 1$, all the integrais in I with a factor $\operatorname{Cos} n q \theta$ or $\operatorname{Sin} N q \theta$ must be of order $1 / \mathrm{Nq}$, so we have

$$
\therefore I=-\frac{Q}{n+2} \int_{0}^{\theta_{0}} d \theta\left(M-\sin ^{2} \frac{\theta}{2}\right)^{1 / 2}
$$

We note that this result is the same as if $g(\dot{\theta})=1, B=0$. Hence we conclude that the poloidal variation in $\delta(r, \theta)$ does not significantly affect the banana guiding center motion to the lowest order in $1 / \mathrm{Nq}$.

In order to calculate the particle diffusion due to the banana drift effect, we follow the derivation in Krommes and Rutherford ${ }^{6}$ to obtain

$$
\begin{aligned}
\Gamma_{\psi}=-\frac{1}{R_{0} q}\left[\frac{B_{0}^{2}}{\Omega}\right]^{2} \int_{0}^{2 \pi} \frac{d \eta}{2 \pi} \int_{0}^{\infty} d E \frac{1}{\nu} \frac{\partial F}{\partial \psi} \\
\quad \times \int_{\mu_{0}}^{\mu_{\max }} \frac{d \mu}{\mu J}\left(\int_{\mu_{\max }}^{\mu} d \mu \frac{\partial J}{\partial \eta}\right)^{2}
\end{aligned}
$$

where we represent the magnetic field as

$$
\underline{B}=\underline{\nabla} \psi \times \underline{\nabla} \eta
$$

and employ $(\psi, \eta, \phi)$ as co-ordinates. To proceed, we need explicit. expressions for $\psi$ and $n$. Let 


$$
\begin{aligned}
n=q \theta & -\phi, \quad n=-\tau \\
\underline{B} & =\frac{\partial \psi}{\partial r} \hat{r} \times \underline{\nabla}(q \theta-\dot{\phi}) \\
& =\frac{\partial \psi}{\partial r} \hat{r} \times\left(q \frac{1}{r} \hat{\theta}-\frac{1}{R} \hat{\phi}\right) \\
& \simeq \frac{\partial \psi}{\partial r} \frac{q}{r}(\hat{\phi}+\theta \hat{\theta})
\end{aligned}
$$

In lowest order,

$$
\begin{aligned}
\frac{\partial \psi}{\partial r} \frac{q}{r} & =\frac{B_{0}}{1+\varepsilon \cos \theta} \simeq B_{0} \\
\psi & \simeq B_{0} \int_{0}^{r} \frac{r}{q} d r
\end{aligned}
$$

We note that

$$
\Gamma_{r}=\frac{\partial r}{\partial \psi} \Gamma_{\psi} .
$$

The ion particle flux is then

$$
\begin{gathered}
\Gamma_{i r}=-(2 / \pi)^{3 / 2} \varepsilon^{3 / 2} q^{2} N^{2} \delta^{2}(r) \cdot\left(c T_{i} / e B R\right)^{2} N_{i} \gamma_{0} H \\
\cdot\left[\frac{N_{i}^{\prime}}{N_{i}}+\frac{E \psi^{-}}{T_{i}}+\left[\frac{\gamma_{1}}{\gamma_{0}}-\frac{3}{2}\right] \frac{T_{i}^{\prime}}{T_{i}}\right] .
\end{gathered}
$$

In a completely analogous fashion, the ion heat flux is

$$
\begin{aligned}
Q_{i r}= & -(2 / \pi)^{3 / 2} \varepsilon^{3 / 2} q^{2} N^{2} \delta^{2}(r)\left(c T_{i} / e B R\right)^{2} T_{i} N_{i} \gamma_{i} H \\
& :\left[\frac{N_{i}^{-}}{N_{i}}+\frac{e \phi^{-}}{T_{i}}+\left[\frac{\gamma_{2}}{\gamma_{i}}-\frac{3}{2}\right] \frac{T_{i}^{\prime}}{T_{i}}\right]
\end{aligned}
$$


where

dind

$$
\begin{aligned}
& \gamma_{0}=\int_{0}^{\infty} d x \frac{x^{5 / 2}}{\nu} e^{-x} \\
& \gamma_{1}=\int_{0}^{\infty} d x \frac{x^{7 / 2}}{\nu} e^{-x} \\
& \gamma_{2}=\int_{0}^{\infty} d x \frac{x^{9 / 2}}{\nu} e^{-x}
\end{aligned}
$$

$$
\begin{aligned}
\nu= & \frac{\pi e^{4} N_{i}}{\sqrt{2 \pi_{i}} T_{i}^{3 / 2} \Lambda} \frac{1}{x^{5 / 2}}\left[2(x / \pi)^{1 / 2} e^{-x}+(2 x-1) E(\sqrt{x})\right] \\
& \cong .94 \nu_{i i} \frac{1}{x^{5 / 2}}\left[2(x / \pi)^{1 / 2} e^{-x}+(2 x-1) E(\sqrt{x})\right]
\end{aligned}
$$

and

$$
H=\frac{4 Q^{2}}{(n+2)^{2}} \int_{0}^{1} \frac{d M}{(2 \varepsilon M+1-\varepsilon)^{1 / 2}}[E(M)-(1-M) K(M)]^{-1}
$$

with

$$
\times\left[\int_{0}^{M} \frac{d M[E(M)-(1-M) K \cdot(M)]}{(2 \varepsilon M+1-\varepsilon)^{5 / 2}}\right]^{2}
$$

$$
v_{i j}=\frac{4 \sqrt{\pi} e^{4} N_{i} \ln \Lambda}{\left.3 \sqrt{m_{i}}\right|_{i} ^{3 / 2}}
$$

$E(M)$ and $K(M)$ are the complete elliptic integrals. Using Eq. (37) in Eq. (36) we obtain 


$$
\begin{aligned}
& \gamma_{0}=\frac{13.7081}{0.94 v_{i i}}=14.583 / v_{i j} \\
& \gamma_{1}=\frac{66.7142}{0.94 v_{i j}}=70.974 / v_{i j} \\
& \gamma_{2}=\frac{393.045}{0.94 v_{i i}}=418.139 / v_{i j}
\end{aligned}
$$

Charge neutrality,

$$
\frac{N_{i}^{\prime}}{N_{i}}+\frac{e \phi^{\prime}}{T_{i}}+\left[\frac{\gamma_{1}}{\gamma_{0}}-\frac{3}{2}\right] \frac{T_{i}^{\prime}}{T_{i}}=0,
$$

leads to

$$
\begin{aligned}
Q_{i r} & =-(2 / \pi)^{3 / 2} \varepsilon^{3 / 2} q^{2} N^{2} \delta^{2}(r)\left(c T_{i} / e B R\right)^{2} N_{i} T_{i} \gamma_{1}\left[\frac{\gamma_{2}}{\gamma_{1}}-\frac{\gamma_{1}}{\gamma_{0}}\right] H \\
& =36.94 \varepsilon^{3 / 2} q^{2} N^{2} \delta^{2}(r) \frac{v_{d r i f t}^{2}}{v_{i j}} N_{i} T_{i} H
\end{aligned}
$$

The integration in Eq. (38) has been carried out numerically for various values of $\varepsilon$. The integral is found to have a numerical value on the order of 0.05176 . The ion heat conductivity coefficient is then

$$
\begin{aligned}
\chi_{i}^{B D} & =36.94 \varepsilon^{3 / 2} \delta^{2}(r) q^{2} N^{2} \frac{v_{d r i f t}^{2}}{v_{i i}} H \\
& =9.23 \varepsilon^{3 / 2} \delta^{2}(r) \frac{N^{2}}{(n+2)^{2}} \frac{v_{d r i f t}^{2}}{v_{i i}} q^{2} Q^{2}
\end{aligned}
$$


5. NUMERICAL EVALUATION OF THE ION HEAT CONDUCTION LOSSES

The ion heat conduction coefficients for the two mechanisms, rippletrapped $(\delta)$ and banana-drift $(B D)$, have been calculated for the parameters typical of the ORNL EPR and compared to the total heat conduction loss due to the neoclassical (NC), trapped particle modes [trapped ion mode (TIM) and trapped electron mode (TEM) 1 or 2] and pseudoclassical (PS) coefficients currently used in the plasma transport simulation codes. The expressions used in the calculations are given below for $\bar{T}_{e} \sim T_{i}$.

$$
\begin{aligned}
& x_{i}^{N C} \simeq \varepsilon^{3 / 2} u^{2} \rho \rho_{e}^{2} v_{e i}\left(\prime \prime_{j} / \prime_{e}\right)^{1 / 2} \\
& x_{e}^{T I M}=x_{i}^{T I M} \simeq \frac{\varepsilon^{5 / 2}}{4} \frac{v_{d r i f t}^{2}}{v_{e i}}\left(R / r_{n}\right)^{2} \\
& x_{e}^{\text {TEM }_{1}} \simeq 3 \varepsilon^{3 / 2} \frac{v_{d r i f t}^{2}}{v_{e i}} \cdot\left(R^{2} / r_{n} r_{T}\right), x_{e}{ }^{T E M_{2}} \simeq c_{2}\left(q^{2} / \Sigma^{2}\right) \rho_{e}^{2} v_{e i} \\
& X_{e}^{P S} \simeq C_{0}\left(q^{2} / \varepsilon^{2}\right) \rho_{e}^{2} \nu_{e i} \\
& x_{i}^{\delta(r)}=46.5 \frac{\delta^{3 / 2} G(\alpha, \beta=0)}{v_{e i}}\left(m_{i} / m_{e}\right)^{1 / 2} v_{d r i f t}^{2} \\
& x_{i}^{\delta(r, \theta)}=46.5 \frac{\delta^{3 / 2} G(\alpha, \beta)}{v_{e i}}\left(m_{i} / m_{e}\right)^{1 / 2} v_{d r i f t}^{2} \\
& x_{i}^{B D}=9.23 \varepsilon^{3 / 2} \delta^{2} \cdot \frac{N^{2}}{(n+2)^{2}} \cdot \frac{v_{d r i f t}^{2}}{v_{e l}}\left(m_{i} / m_{e}\right)^{1 / 2} q^{2} Q^{2} \\
& x_{i}=x_{i}^{N C}+x_{i}^{T I M} \\
& x_{e}=x_{e}^{T I M}+x_{e}^{P S}+\min x_{e}^{\text {TIM } 1 \text { or2 }}
\end{aligned}
$$


where $\quad r_{n}=[1 / n d n / d r]^{-1}, \quad r_{T}=[1 / T d T / d r]^{-1}, \quad c_{0} \sim 4-10$, $C_{2} \simeq 0.06 \varepsilon^{1 / 2}(d$ ln $T / d$ ln $n)\left(m_{j} / m_{e}\right)\left(B_{\theta} / \theta B_{T}\right), \theta=r_{n} / L_{s} ; L_{s}^{-1} \simeq\left(r / R_{0} q^{2}\right)$ $(\partial q / \partial r), \rho_{e}$ is the electron Larmor radius in the toroidal field, $q=\varepsilon B_{T} / B_{\theta}, \nu_{e i}=1.6 \times 10^{4}<Z>\left(n_{0} / 10^{13}\right) / T^{3 / 2}(k e V)$.

In the ORNL EPR design, $\delta$ takes on its maximum value of about $2.2 \%$ at the outer edge of the plasma column. Figure 4 shows the distribution of the field ripple over the cross section of the ORNL EPR. Equation (4) satisfactorily approximates the field in the cross section of plasmas, thus,

$$
\delta(r, \theta)=\left[1.2 \times 10^{-4}+2.2 \times 10^{-2}(r / a)^{4}\right] \exp \left[-(2.8 \theta / \pi)^{2}\right]
$$

with $n=4, N=20, \delta_{a}=2.2 \times 10^{-2}, \delta_{0}=1.2 \times 10^{-4}, \beta=\left(2.8 / \pi^{2} \simeq 0.794\right.$.

In the calculations, a parabolic temperature profile, $T=T_{0}\left(1-r^{2} / a^{2}\right)$, has been assumed with $T \sim n^{2}, n=n_{0}\left(1-r^{2} / a^{2}\right)^{1 / 2}$, and the safety factor $q$ is calculated assuming a current density profile that varies 1 ike $T^{3 / 2}$. The results are shown in Fig. 5. Although the heat conduction coefficients associated with the ripple trapping and banana-drift are comparable to those calculated from the ion neoclassical and electron pseudoclassical coefficients, the trapped-ion and trappedelectron mode coefficients are about 20 times larger at their peaks, if poloidal angle effects are ignored $(\beta=0)$. The inclusion of poloidal angle effects reduces the losses associated with ripple trapping by about a factor of 10 to 15 , but does not significantly change the banana-drift losses. The overall enhanced ion heat loss due to ripples is found to have a negligible effect on plasma confinement for the 
ORNL-EPR design. However, if one assumes better confinement - for example, if ignition is to be achieved at a higher toroidal field (say 70-85 kG) - energy losses must be no larger than one-tenth of the trapped particle losses. Even under this condition, the enhanced heat losses due to the $2.2 \%$ edge field ripple are less than $10 \%$ of that due to trapped particle instabilities.

\section{ACKNOWLEDGMENTS}

The authors wish to thank.D. G. McAlees and M. Roberts for stimulating this detailed examination for the EPR, and T. Uckan for. carrying out the numerical intecrations. 
Table 1. Typical Parameters

\begin{tabular}{|c|c|c|}
\hline & ORMAK Upgrade & ORNL EPR \\
\hline Major radius $(\mathrm{cm})$ & 90 & 675 \\
\hline Minor radius $(\mathrm{cm})$ & 30 & 225 \\
\hline Number of coils & 24 & 20 \\
\hline$\delta(a)$ & $4.2 \%$ & $2.2 \%$ \\
\hline$\delta(0)$ & $0.009 \%$ & $0.012 \%$ \\
\hline$\dot{n}_{0}\left(\# / \mathrm{cm}^{3}\right)$ & $7 \times 10^{13}$ & $8 \times 10^{13}$ \\
\hline$T_{i}(k e V)$ & $2-3$ & $9-10$ \\
\hline $\mathrm{B}_{\mathrm{To}}(\mathrm{KG})$ & 45 & 48 \\
\hline$q(a)$ & $3-4$ & 2.5 \\
\hline$z_{\text {eff }}$ & 4 & 2 \\
\hline$E_{t h}(a)(k e v)$ & 0.3 & 3 \\
\hline$E_{t h}(0)(k e V)$ & 30 & 150 \\
\hline$E_{*}(a)(k e V)$ & 10 & 48 \\
\hline$E_{\star}(0)(k e V)$ & 100 & 380 \\
\hline
\end{tabular}




\section{REFERENCES}

1. N. A. Uckan, K. T. Tsang, and J. D. Callen, "Toroidal Field Ripple Effects in Large Tokamaks," Sixth Symposium on Engineering Problems of Fusion Research (IEEE), San Diego, 1975 (proceedings to be published).

2. T. E. Stringer, Nucl. Fusion 12, 289 (1972).

3. J. W. Connor and R. J. Hastie, Nucl. Fusion 13, 221 (1973).

4. J. N. Davidson, Bul1. Am. Phys. Soc. 20, 1240 (1975).

5. M. Roberts and E. S. Bettis, (eds.), "Oak Ridge Tokamak EPR Study, Reference Design," ORNL/TM-5042 (November 1975)

6. J. A. Krommes and P. H. Rutherford, Nucl. Fusion 14, 695 (1974). 
21

FIGURE CAPTIONS

Fig. 1. $\delta$ versus "critical" ion energies.

Fig. 2. Variation of diffusion coefficient $D$ and heat conductivity $X$ with collision frequency $\nu$.

Fig. 3. $G(\alpha, \beta)$ versus $\alpha$.

Fig. 4. Constant ripple contours of ORNL EPR.

Fig. 5. Heat conduction coefficients versus plasma radius for the ORNL EPR design parameters. 
ORNL DWG 76-4238

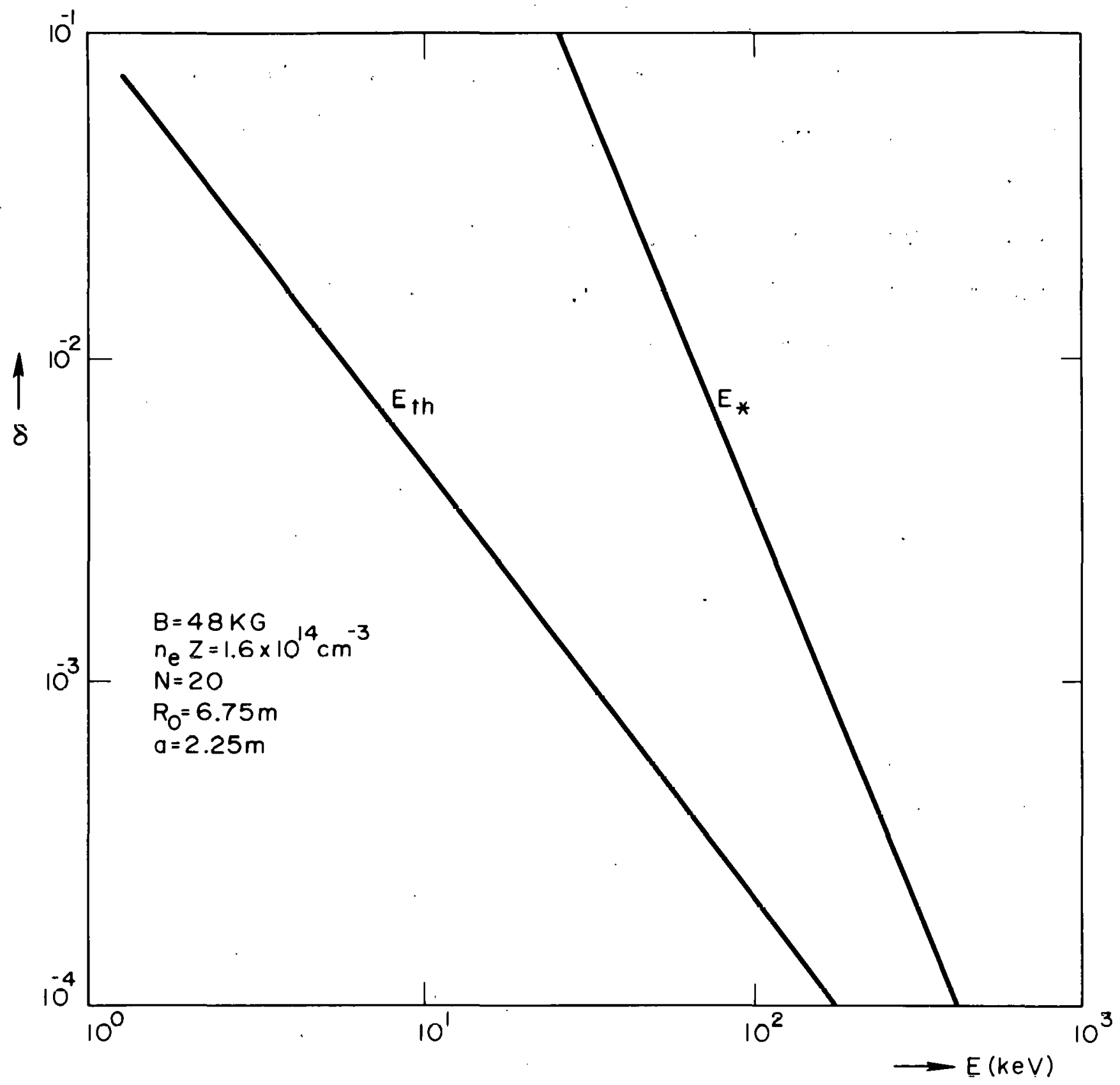

Fig. 1 
ORNL DWG 76-4237

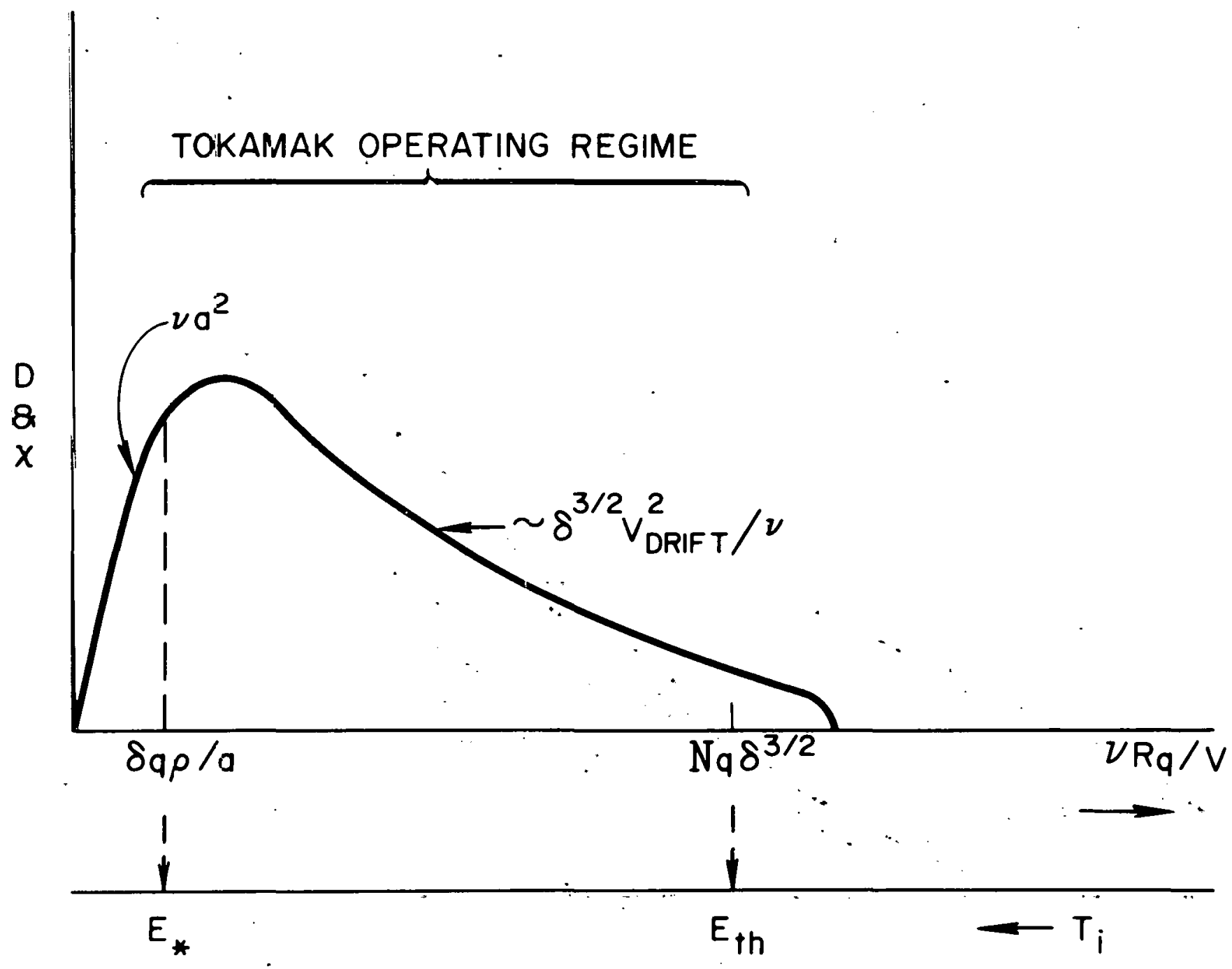

Fig. 2 


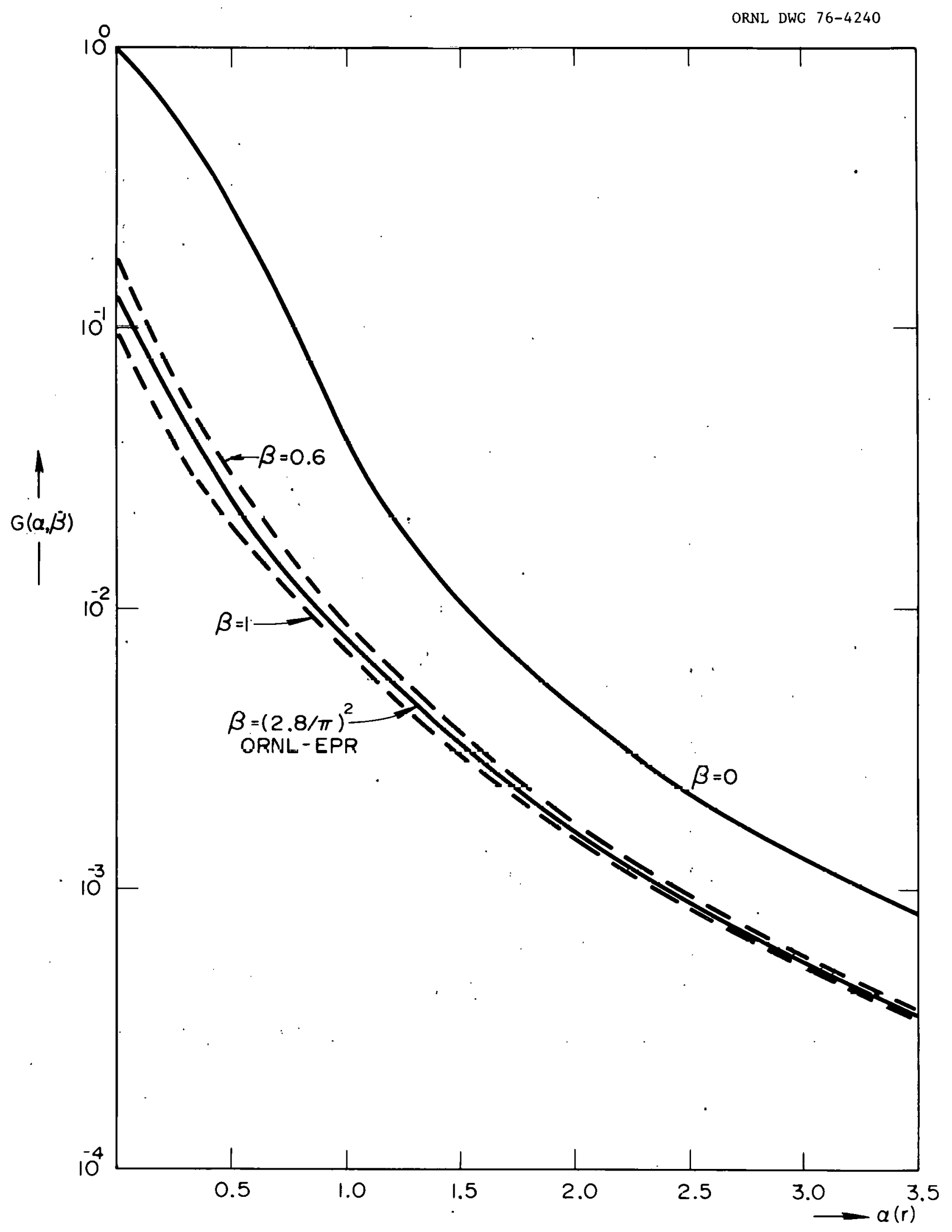

Fig. 3 


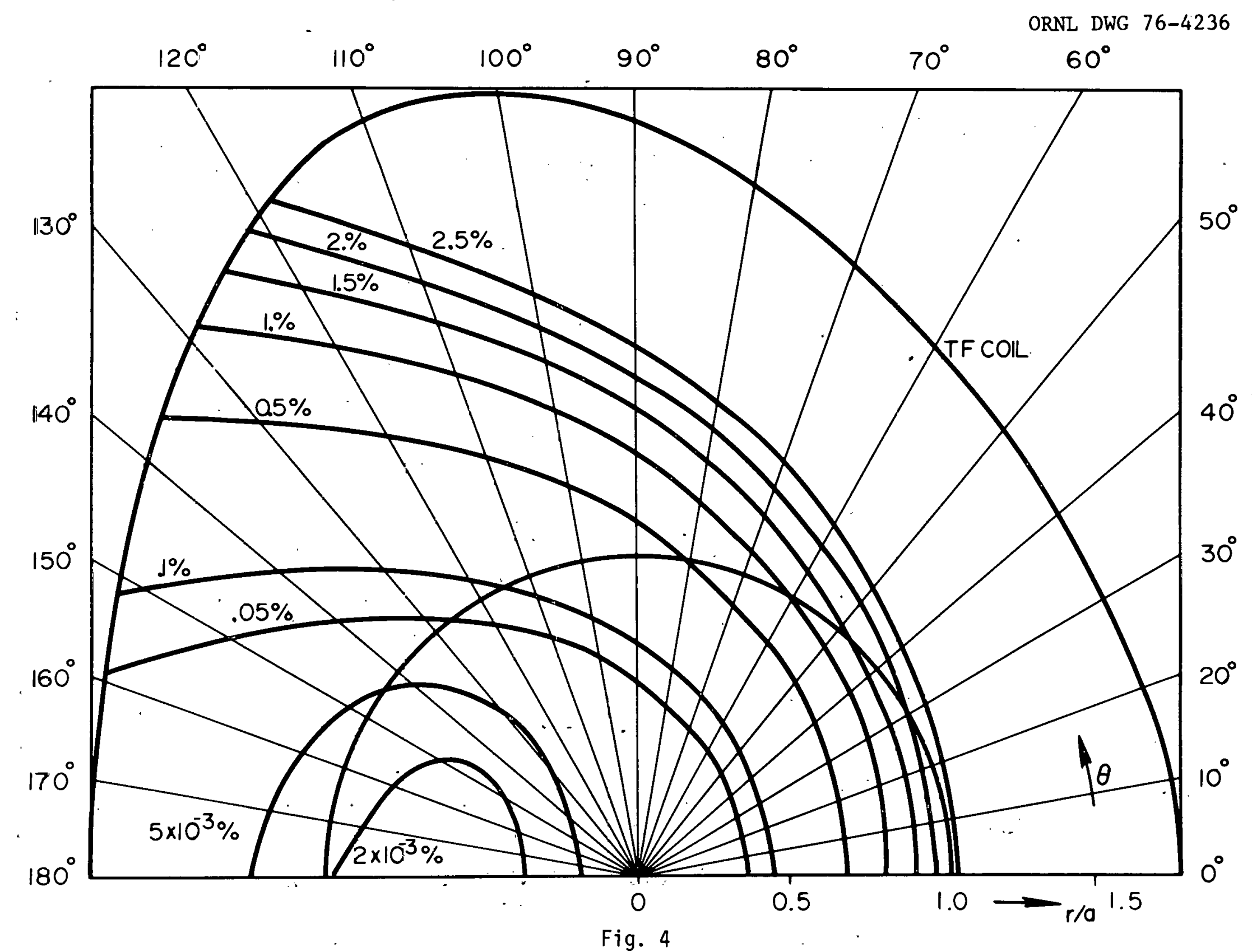

ơ 


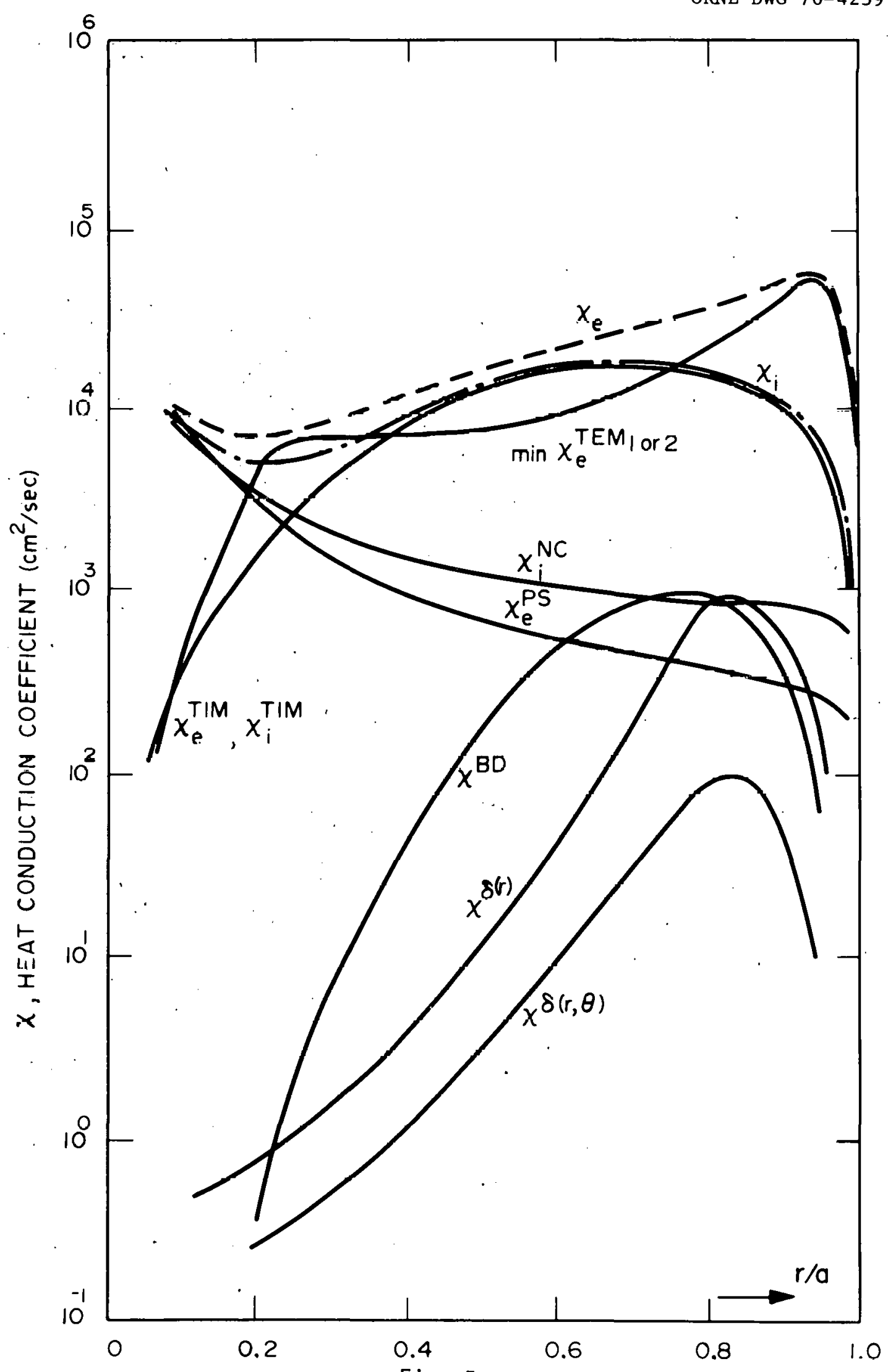

Fig. 5 
INTERNAL DISTRIBUTION

ORNL/TM-5438

1-3. Lab Records

4. Lab Records - RC

5. $Y-12$ Document Reference

6-7. Central Research Library

8. Thermonuclear Library

9. ORNL Patent Office

10. J. D. Callen

11. J. F. Clarke.

12. R. A. Dory

13. G. G. Kelley

14. D. G. McAlees

15. 0. B. Morgan

16. M. W. Rosenthal

17-43. N. A. Uckan

EXTERNAL DISTRIBUTION

44. Plasma Physics Library, Plasma Physics Laboratory, Princeton Univ., Forrestal Campus, P.0. Box 451, Princeton, NJ 08540

45. Controlled Thermonuclear Research Library, Lawrence Livermore Laboratory, P.0. Box 808, Livermore, CA 94550

46. Q Division Library, c/o F. L. Ribe, Los Alamos Scientific Laboratory, P.0. Box 1663, Los Alamos, NM 87544

47. Controlled Thermonuclear Research Library, c/o Weston M. Stacey, Jr., Argonne National Laboratory, 9700 S. Cass Ave., Argonne, IL 60439

48. CTR Computer Center, C/O Dr. John Killeen, Lawrence Livermore Laboratory, P.0. Box 808, Livermore, CA 94550

49. Librarian, CuTham Laboratory, U.K. Atomic Energy Authority, Abingdon, 0xon, OX14, 3DB, United Kingdom

50. Ruth Lengye, Bibliothek, Max Planck Institut für Plasmaphysik, 8046 Garching bei München, Federal Republic of Germany

51. Library, Centre de Récherches en Physique des Plasma, 21 Avenue des Bains, 1007, Lausanne, Switzerland

52. A. M. Dupas, Documentation S.I.G.N., Department de La Physique du Plasma, Et de La Fusion Controlée, Association EURATOM-CEA, Sur La Fusion, Centre d'Etudes Nucleaires, BP 85 Centre DU TRI 38041 Grenoble Cedex (France)

53. Bibliotheque, Service du Confinement des Plasmas, C.E.A., B.P. No. 6,92 , Fontenay-aux-Roses (Seine) France 
54. Library, International Centre for Theoretical Physics, Trieste, Italy

55. Library, Laboratorio Gas Ionizati, Frascatti, Italy

56. V. E. Ivanov, Physical-Technical Institute of the Ukranian Academy of Sciences, Sukhumi, U.S.S.R.

57. M. S. Rabinovich, Lebedev Institute of Physics, Academy of Sciences of the U.S.S.R., Leninsky Prospect 53, Moscow, U.S.S.R.

58. Thermonuclear Laboratory, Kurchatov Institute of Atomic Energy, 46 Ulitsa Kurchatova, P.0. Box 3402, Moscow, U.S.S.R.

59. Library, Institute for Plasma Physics, Nagoya University, Nagnya, Japan 464

60. Library, FOM-Institut voor Plasma-Fysica, Rijnhuizen, Jutphaas, Nethẹrlands

61. Plasma Physics Group, Department of Engineering Physics, Australian National University, P.n. Rnx 4, Canberra A.6.T. 2600 Australia

62. Thermonuclear Library, Japan Atomic Energy Research Institute, Tokai, Naka, Ibaraki, Japan

63. CTR Reading Room, C/o Prof. Dieter J. Sigmar, Room 37-391, MIT, Cambridge, MA 02139

64. CTR Reading Room, c/o Prof. D.W. Kerst, Dept. of Physics, Sterling Hall, Univ. of Wisconsin, Madisnn, WT 53706

65. CTR Reading Room, c/o Prof. I. B. Bernstein, Yale Univ., New Haven, CT 06510

66. Center for Plasma Physics and Thermonuclear Research, Univ. of Texas, Physics Building 330, Austin, TX 78712

67. CTR Reading Room, c/o Prof. B. D. Fried, Physics Dept.., Univ. of Calitornia, Los Angeles, CA 90024

68. CTR Keading Room, c/o Prof. David C. Montgomery, Physics \& Astroriully Dept., Untv. of Iowa, Iowa Cily, IA 52240

69. Magneto-Fluid-Dynamics Library, Courant Inst. of Math. Sci., New York Univ., 251 Mercer St., New York, NY 10012

70. CTR Reading Room, c/o Prof. Allan N. Kaufman, Physics Dept., Univ. of California, Berkeley, CA 94720

71. CTR Reading Room, c/o Prof. W. B. Thompson, Physics Dept., Univ. of California, San Diego, La Jolla, CA 92037. 
72. CTR Reading Room, c/o Prof. Alvin W. Trivelpiece, Dept. of Physics \& Astronomy, Univ. of Maryland, College Park, MD 20742

73. CTR Reading Room, c/o Prof. T. Kammash, 103 Research Admin. Bldg., N. Campus, Univ. of Michigan, Ann Arbor, MI 48105

74. CTR Reading Room, c/o Dr. Ravi N. Sudan, Phillips Hall, Cornell Univ., I thaca, NY 18450

75. Prof. Marshall N. Rosenbluth, Institute for Advanced Study, Princeton, NJ 08540

76. CTR Reading Room, c/o Prof. R. Gross, Plasma Research Lab., Columbia Univ., New York, NY 10027

77. CTR Reading Room, c/o Prof. Roy Gould, California Inst. of Tech., Pasadena, CA 91103

78. Dr. Nicholas A. Krall, Science Applications, Inc., P.0. Box 2354, 1200 Prospect St., La Jolla, CA 92037

79. CTR Reading Room, c/o Dr. Jay P. Boris, Plasma Physics, Naval Research Laboratory, Washington, DC $\cdot 20390$

80. CTR Library, General Atomic Co., P.0. Box 81608, San Diego, CA 92138

81. CTR Library, c/o Dr. Alan F. Haught, United Technologies Research Labs, East Hartford, CT 06108

82. Dr. Robert E. Price, Division of Controlled Thermonuclear Research, Energy Research and Development Administration, Washington, DC 20545

83. Dr. Bennett Miller, Division of Controlled Thermonuclear Research, Energy Research and Development Administration, Washington, DC 20545

84. Dr. Arthur Sleeper, Division of Controlled Thermonuclear Research, Energy Research and Development Administration, Washington, . DC 20545

85. Dr. Walter Sadowski, Division of Controlled Thermonuclear Research, Energy Research and Development Administration, Washington, DC 20545

86. Dr. D. H. Priester, Division of Controlled Thermonuclear Research, Energy Research and Development Administration, Washington, DC 20545

87. Dr. Paul H. Rutherford, Princeton Plasma Physics Lab., Princeton Univ., Princeton, NJ 08540 
88. Dr. L. D. Pearlstein; L-388, Lawrence Livermore Laboratory, P. 0. Box 808, Livermore, CA 94550

89. Dr. J. P. Friedberg, Los Alamos Scientific Laboratory, Los Alamos NM 87544

90. Dr. David W. Ross, Center for Plasma Physics \& Thermonuclear Research, Dept. of Physics, Univ. of Texas, Austin, TX 78712

91. Dr. Gareth E. Guest, General Atomic Co., P.0. Box 81608, San Diego, CA 92138

92. Dr. Claude Mercier, Service du Theorie des Plasmas, Centre d'Etudes Nucleaires, Fontenay-aux-Roses (Seine) France

93. Mr. J. B. Taylor, Culham Laburatory, UKAtA Abingdon, Oxon, 0X14 3DB, United Kingdom

94. Dr. D. Pfirsch, Institule for Plasma Physics, 8046 Garching be1 München, Federal Republic of Germany

95. Dr. V. D. Shafranov, I. V. Kurchatov Inst. of Atomic Energy, 46 Ulilsd Kurchatova, P.O. Box 3402 , Moscow, U.S.S.R.

96. Dr. Harold Grad, Courant Inst. of Math. Sci., New York Univ., 251 Mercer St., New York, NY 10012

97. Dr. J. G. Cordey, Culham Laboratory, UKAEA, Abingdon, Oxon, 0x14, 3DB, United Kingdom

98. Dr. David Baldwin, L-388, Lawrence Livermore Lab., P.0. Box 808 , Livermore, CA 94550

99. Prof. Bruno Coppi, Mnpt, of Physics, M.I.T., Canuridye, MA $0 \dot{2} 139$

100. Dr. Harold P. Furth, Princeton Plasma Physics Lab., Princeton Univ., P.0. Box 451, Princeton, NJ 08540

101. Research \& Technical Support Div., ORO, ERDA

102-128. Tech. Information Center, ERDA, ORO 